This item was submitted to Loughborough's Research Repository by the author.

Items in Figshare are protected by copyright, with all rights reserved, unless otherwise indicated.

\title{
Surface water in temporary humanitarian settlements
}

PLEASE CITE THE PUBLISHED VERSION

http://dx.doi.org/10.3362/1756-3488.2017.004

\section{PUBLISHER}

(C) Practical Action Publishing

\section{VERSION}

AM (Accepted Manuscript)

\section{PUBLISHER STATEMENT}

This work is made available according to the conditions of the Creative Commons Attribution-NonCommercialNoDerivatives 4.0 International (CC BY-NC-ND 4.0) licence. Full details of this licence are available at: https://creativecommons.org/licenses/by-nc-nd/4.0/

\section{LICENCE}

CC BY-NC-ND 4.0

\section{REPOSITORY RECORD}

Reed, Brian. 2019. "Surface Water in Temporary Humanitarian Settlements". figshare. https://hdl.handle.net/2134/23637. 


\section{Surface water in temporary humanitarian settlements}

Brian Reed BSc (Hons)(Dunelm), PGDip (Lond), MSc (N'cle), CEng, CEnv, C.WEM, MICE, MCIWEM, FHEA

Lecturer

Water, Engineering and Development Centre (WEDC)

School of Civil and Building Engineering

The John Pickford Building

Loughborough University

Leicestershire LE11 3TU UK

\section{Abstract (214 words)}

In the Humanitarian Innovation Fund Gap Analysis for water, sanitation and hygiene issues (Bastable and Russell 2013), field staff identified environmental management of surface water as an area of concern, although this was not reflected at a head office level. This difference of perspectives could be an under reporting of this aspect of environmental sanitation to the global humanitarian community or a failure of experts to communicate the required response to surface water management in camps for displaced people. Reviewing core humanitarian engineering texts and global standards, this paper sets out the current state of the art and shows that there is a lack of clarity in the "ownership" of the problem and the established responses are disjointed and poorly articulated, especially at field staff level. Since the core texts have been written, there has been a change in the way surface water is being managed in urban areas. Sustainable urban drainage practices may have potential in resource poor but densely populated situations such as some refugee camps. The paper highlights the lack of adequate advice in both content and delivery mechanisms. More gaps and challenges were identified than solutions, but this is research narrowed down the gaps identified in 2013 to more specific issues, which is a step further to solving the problem. 


\section{Introduction}

\subsection{Learning from our mistakes}

In the early 1990s, the author attended a short residential field course organised by RedR on providing basic services for displaced people. Working in small teams, the participants had to propose solutions for water, sanitation, camp layout and other facilities. All the teams except one suggested an orderly pattern of settlement, as shown in the text books, on a large flat area of ground adjacent to a large river. The remaining team (which was not the author's) had a complex pattern of settlement, spread out along the steep side of the valley. They had realised that the term "flood plain" did imply that the area next to the river did flood and the inconvenience of an awkward settlement layout and increased distance from the water source was outweighed by the problems that would occur when the river level rose.

Twenty-five years later, the author is now running similar training courses at a variety of levels and has learnt from this early error. As part of a long-running course for field staff working for a large humanitarian organisation, each participant has to give a short presentation on a water, sanitation or hygiene (WASH) problem they have encountered in practice. Over the last ten years, a series of case studies have been presented relating to surface water problems, from localised runoff issues to larger scale, seasonal inundation. Whilst not being major acute issues, these have been persistent chronic problems, with impacts on other aspects such as flooding of latrines and waste pits, damage to structures and roads due to erosion, impediments to pedestrian and vehicular traffic and a general adverse impact on living conditions. In discussions after each case study, the solutions are not always apparent and some solutions only addressed individual impacts rather than the underlying cause. As a sector, the problem is not always recognised and the solutions are not clear. This paper explores what is known about this topic, or, more importantly, what is not known. Rather than providing immediate answers, it focuses on the core issues. This analysis has been based on a series of focus groups, case studies and a literature review, within a wide context of humanitarian situations in urban and rural areas of low- and middle-income countries relating to both localised flooding and widespread inundation. 


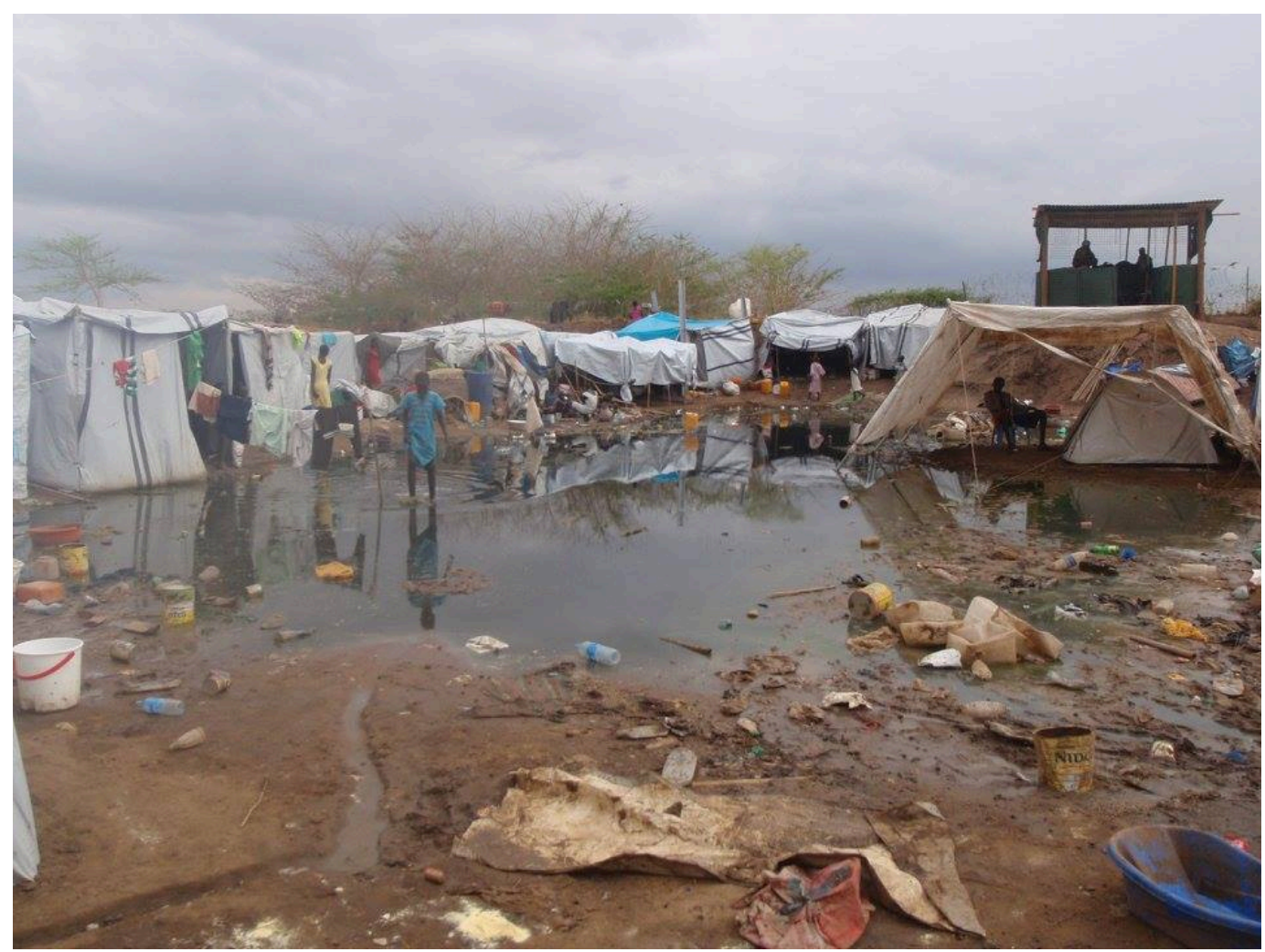

Figure 1: Ponding surface water causing a poor living environment (Source: V Hammond)

\subsection{The problems of poor surface water management}

In an emergency, water, sanitation and hygiene are basic humanitarian requirements. Sanitation does not just include the safe disposal of excreta but wider aspects, sometimes called "environmental sanitation". This encompasses a range of contaminants, polluting activities and aspects of the environment apart from excreta disposal, such as:

- Air pollution (especially indoors due to cooking stoves);

- Solid waste (also called rubbish, garbage, litter);

- Wastewater from activities other than excreta disposal, such as sullage (or greywater) from laundry and bathing; and

- Poorly managed surface runoff.

Local surface runoff is mainly from rainwater, but leaks from water supply pipes, spillage of water being collected and carried home and poor disposal of sullage (greywater) can also contribute to flows. Rainfall varies from place to place and from time to time, making standardized approaches difficult. Even areas with low annual rainfall can experience infrequent but intense, short duration storms. Larger scale impacts can be caused by inundation by rivers or groundwater arising from rainfall further away (Reed, Parkinson and Nalubega 2001.

Poorly managed surface runoff (for example in figure 1) has interrelated impacts:

- the quality of the water is of concern, as it picks up material at it flows over the ground. Where open defecation is practised, this water will include faecal matter, which can then pollute the wider environment, including water sources, fields and the area around people's houses; 
- the quantity of the water can lead to erosion of roads or around structures such as water points or latrines;

- large flows of water can inundate dwellings, damaging possessions and making the shelter uninhabitable;

- flows can cause latrine pits to overflow

- flows can fill refuse pits;

- standing water can become a breeding area for mosquitoes;

- damp soils can provide a habitat for hookworm; and

- saturated soils can create muddy conditions, unpleasant for pedestrians and rendering some roads impassable (figure 2).

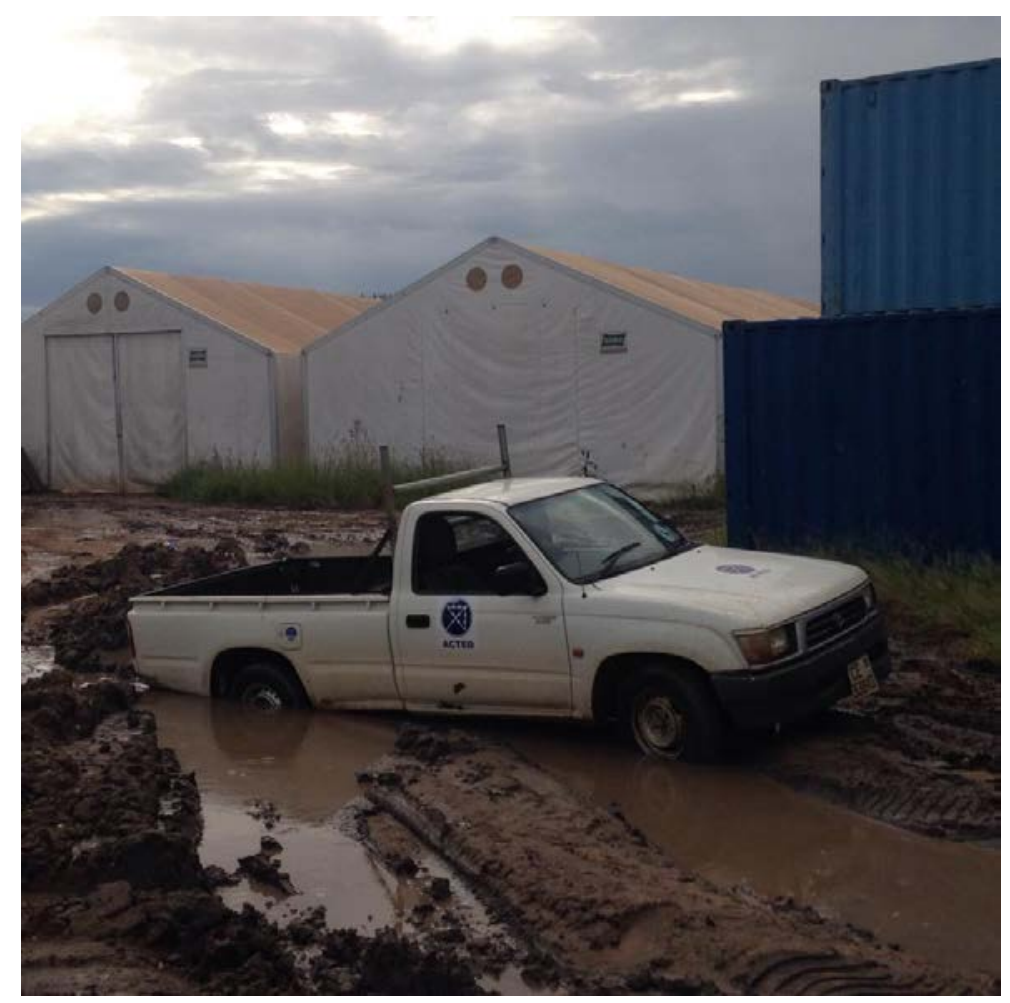

Figure 2: Poor drainage hinders transport (Source: V Hammond)

\section{Health issues}

Specific links between surface water and diarrhoeal disease transmission are more difficult to find, although this is a primary drainage concern in SPHERE (2011). This is a challenge that has been around for over 150 years as the following quote about the Nottingham cholera outbreak in 1832 shows (Chambers J D quoted in McDonald J D, 1983).

"... Altogether there were 930 attested cases and 330 deaths. It was generally agreed at the time that the lower parts of the town had been the worst affected and that the higher streets, built on porous sandy rock, had been almost immune. It might be supposed that such a calamity would have driven home the obvious inference that the drainage and ventilation of the houses in the lower part of the 
town required attention; the town fathers, however, contented themselves by acquiring new burial grounds"

More recently, Taylor et al (2015) looked at WASH interventions and concluded that only a few transmission routes for cholera have been studied and even those studies that have been done are limited in terms of quality and quantity. During their research they found no significant mentions of drainage, the nearest reports being Azurin and Alvero (1974) who looked at both water and excreta disposal but not surface water management (Taylor pers comm).

\section{Environment}

There are also environmental considerations, as SPHERE (2011) states:

"Erosion: Shelter and settlement... should be planned to retain ... vegetation to stabilise the soil and to maximise the opportunities for ... protection from the climate. Natural contours should be used for such elements as roads, pathways and drainage networks in order to minimise erosion and flooding. Where this cannot be achieved, any likely erosion should be contained through the provision of excavated drainage channels, piped drainage runs under roadways or planted earth banks to minimise water run-off" (see figure 3 ).

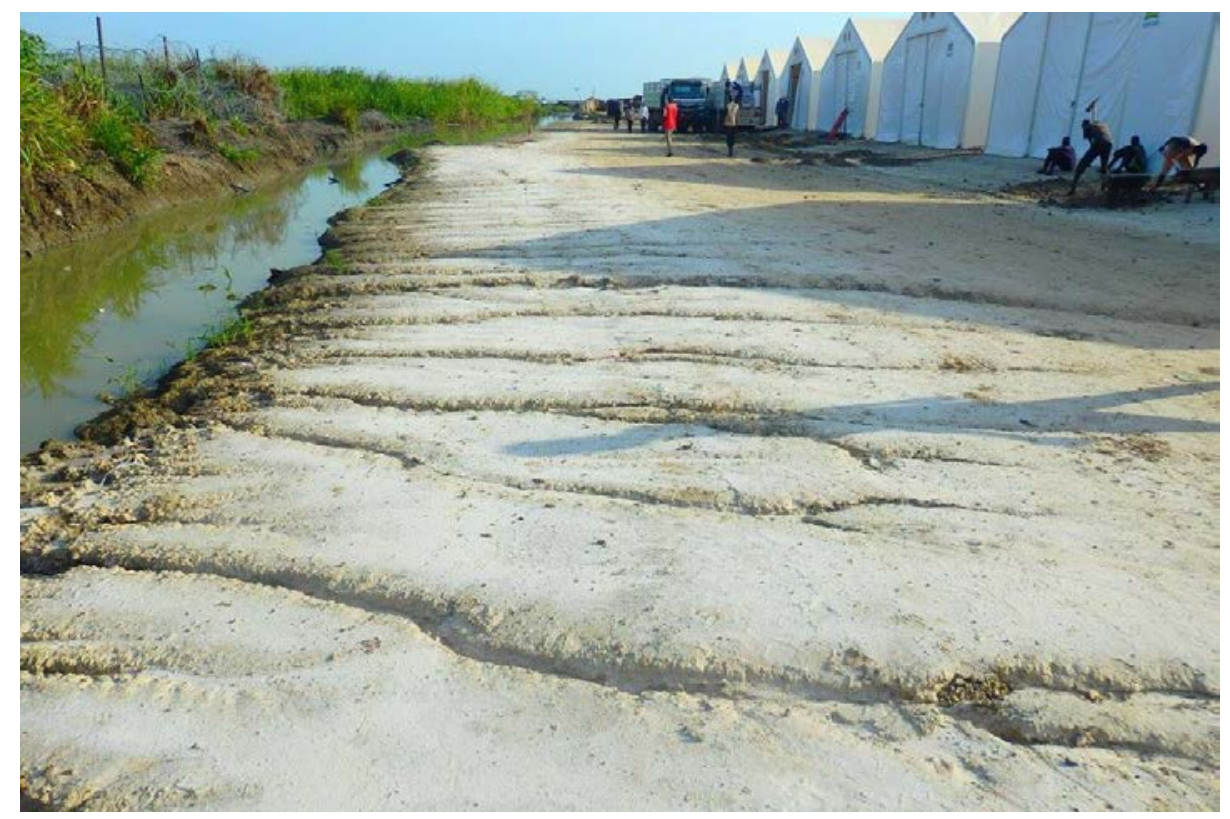

Figure 3: Erosion of road due to runoff from a camp (Source: $V$ Hammond)

\section{Causes of surface water problems}

In the natural cycle of water, rainfall will initially infiltrate into the ground, form puddles on the surface and eventually flow over the ground, resulting in problems locally or further downstream. Compaction of soils for paths, clearing of vegetation and creating impermeable surfaces (such as roads or shelters) decreases the ability of water to infiltrate into soils. Dense emergency settlements, with a high proportion of shelters such as tents or basic houses with corrugated iron roofs, create impermeable areas. This increases the proportion of 
water that ponds on the surface and eventually flows downhill. Not only does the volume of water flowing over the surface increase, the flows tend to be more sudden and have higher peak flow rates, which in turn can lead to erosion. The lack of infiltration can lead to a local reduction in groundwater recharge.

Planned camps or informal, rapid settlement can take place on areas currently unoccupied. Intermittent flooding is one reason why land may not have been built upon (see figure 4). Local authorities may allocate or allow settlement on this land, even though it might not be suitable from a drainage perspective. On a smaller scale, buildings may be built on flow paths before seasonal runoff becomes apparent.

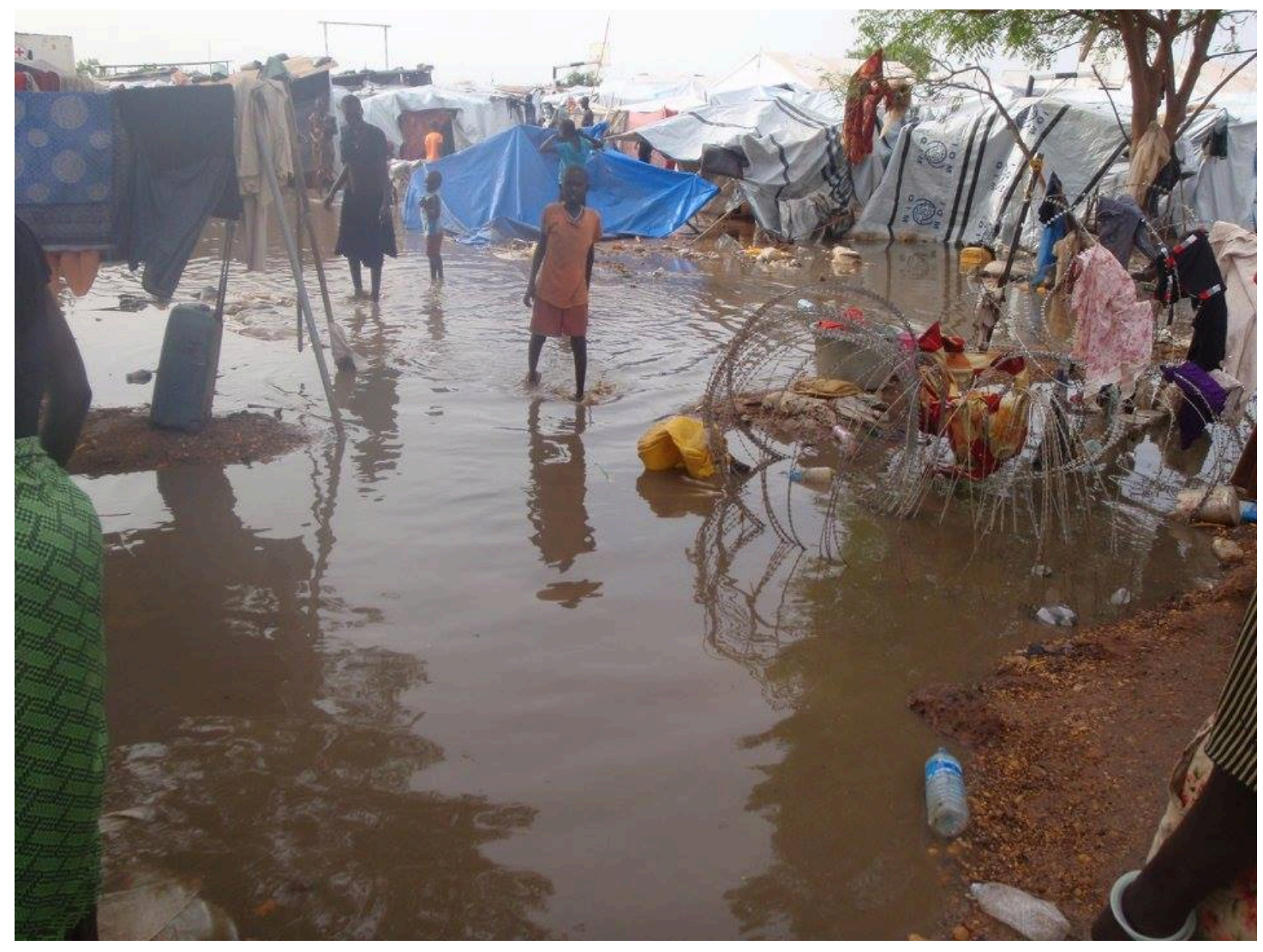

Figure 4: Surface water flooding in a camp for displaced people (Source: V Hammond)

\section{Current status of surface water in emergency situations}

\subsection{A knowledge gap or lack of awareness?}

The series of case studies presented by the field workers on the training courses reflects a pattern of concern shown in the Humanitarian Innovation Fund (HIF) gap analysis (Bastable and Russell, 2013). A wide range of humanitarian professionals at various levels and locations were consulted on the issues that they considered require research and innovation $(n=909)$. Unsurprisingly "latrines without pits" was ranked first (which includes pits in areas that flood), the issue being raised 37 times in consultations, but "general drainage" was ranked 16/ 58 (raised 15 times). Other related issues included "environmental concerns" (including poor drainage) (ranked 20/58, raised 12 times) (Table 1). Aggregating these various suggestions under a heading of "managing water on the surface", this would bring mentions of the topic to 35 occurrences, making it the 
second ranked issue. This also illustrates the problem of nomenclature and definition, an issue that also could be applied to other areas, such as hygiene promotion.

Table 1: List of emergency WASH issues raised (adapted from Bastable and Russell, 2013)

\begin{tabular}{|l|c|c|c|c|c|c|c|}
\hline Issue & $\begin{array}{l}\text { Literature } \\
\text { review }\end{array}$ & $\begin{array}{l}\text { Focus group } \\
\text { discussion } \\
\text { (beneficiaries) }\end{array}$ & $\begin{array}{l}\text { Workshops } \\
\text { (fieldworkers) }\end{array}$ & $\begin{array}{l}\text { On line } \\
\text { survey }\end{array}$ & $\begin{array}{l}\text { Global } \\
\text { WASH } \\
\text { Cluster }\end{array}$ & Donor & Total \\
\hline $\begin{array}{l}\text { General drainage, from } \\
\text { showers and wash } \\
\text { units e.g. rapid onset }\end{array}$ & 1 & 5 & 4 & 5 & & & 15 \\
\hline $\begin{array}{l}\text { Environmental } \\
\text { concerns (wastage at } \\
\text { pump, poor drainage) }\end{array}$ & 1 & & & 11 & & & 12 \\
\hline $\begin{array}{l}\text { Management of water, } \\
\text { latrine, waste and } \\
\text { drains during and after } \\
\text { emergency }\end{array}$ & & & & 4 & 1 & & 5 \\
\hline $\begin{array}{l}\text { Rainwater catchment } \\
\text { and reuse of water for } \\
\text { garden }\end{array}$ & & & & & & & \\
\hline Total & 2 & 5 & 5 & 22 & 1 & & 35 \\
\hline
\end{tabular}

Another interesting aspect was the pattern of concern. The surface water issues were mentioned as an issue 35 times, but of these, the responses came from beneficiaries and fieldworkers, rather than literature and donors or the WASH cluster. This disparity or "known unknowns" can be interpreted in two ways using Johari's window.

- the problem being "solved", so experts knew the solution but poor dissemination and training meant that people working in the field were not aware of this solution, or

- the problem being unknown, with field workers being faced with the situation but experts not realising the challenge, perhaps due to poor reporting. This communication is compounded as access to areas experiencing surface water problems is reduced due to the surface water problem itself, making external inspection difficult

If the first possibility is true, then the gap can be filled by better dissemination of practical solutions. If the second possibility is true, then awareness of the issue needs to be raised and solutions need to be proposed. The gap could be a mixture of absolute knowledge gaps (with no known solution) and lack of awareness (by fieldworkers or head office staff).

\subsection{Focusing on the problem}

In an attempt to narrow down the issue and distinguish between knowledge gaps and lack of awareness, the author facilitated a focus group with experienced field staff $(n=15)$ who had been working in the sector for three years at least. Several themes emerged from this discussion.

\subsubsection{A patchy Problem}

Only about half the staff had experienced major problems with surface water and the pattern had strong spatial and temporal aspects. The experience from South Sudan, Ethiopia and Chad showed that soil type 
(especially black cotton soils) and topography (very flat areas) played an important role. Seasonal patterns (pronounced wet and dry seasons) or short but intense rainfall were other contributing factors. Local context therefore was important rather than this being a widespread challenge with generic solutions.

\subsubsection{III-defined problem}

Whilst the author was asking about the management of surface water due to rainfall (surface runoff), the participants interpreted this as any water on the surface, including split water around water distribution points and sullage (grey water) from laundry and bathing, as well as the larger scale fluvial inundation. None of the participants were aware of the standards expected for surface water management, making the severity or extent of the problem difficult to quantify.

\subsubsection{More problems than solutions}

The majority of the focus group discussion was spent describing the poor living conditions due to poor surface water management. This impact was compounded by the pollution of the runoff by wastewater, sullage and excreta. Erosion and inundation of pit latrines was a common observation (figure 5). The complexity of this discussion illustrated a confused mixture of causes and impacts. 


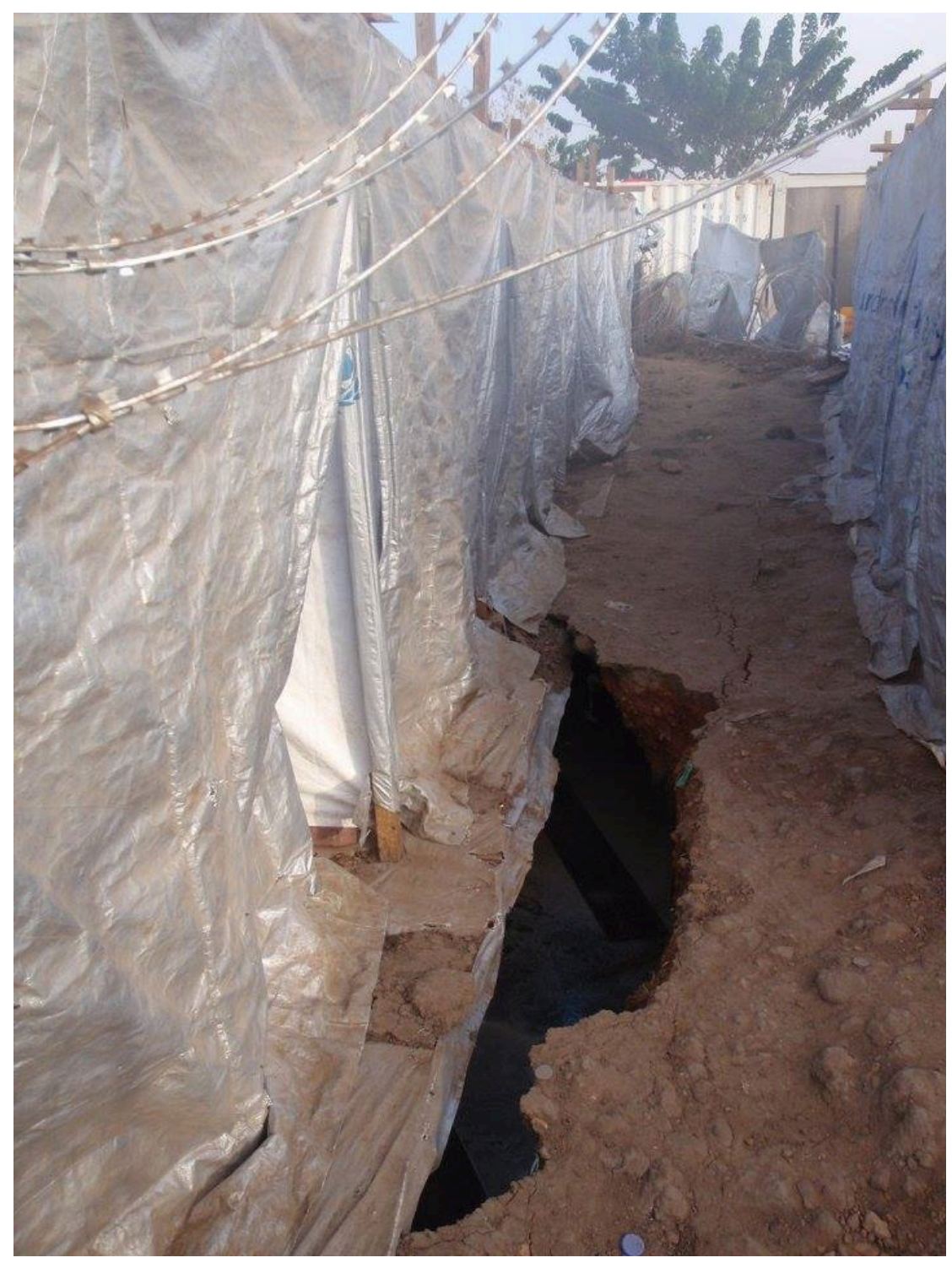

Figure 5: Erosion of a pit latrine (Source: $\vee$ Hammond)

\subsubsection{Standard solutions not working}

Some participants had tried solutions such as soakaways and filter mounds, but without success. A failed soakaway solution (which was actually for water from showers) was eventually remedied by constructing a series of smaller pits as the original solution had been undersized for the infiltration capacity of the soil. The filter mounds were dismissed as not being viable although research (e.g. Phelps and Griggs, 2005) would suggest that design or construction were the problem rather than the underlying technique. Successful interventions did seem to be notable by their absence.

\subsubsection{Wider spatial problem}

One on-going case in South Sudan was a medical facility that has been built on an area of sloping ground. It receives runoff from the area uphill from the compound, but various walls and buildings within the compound and raised roads and undersized culverts downhill restrict the flow, causing ponding within the compound. Thus some of the causes lie physically outside the area managed by the organisation. 


\subsection{Information from field staff}

As part of this research, the author requested photographs from field staff from a different organisation. These revealed further issues, such as the presence of security ditches around camps (figure 6), the use of surface water drains as a water source (for bathing and laundry), (figure7) and flotation of buried cess pits that had not been anchored down (figure 8 ).

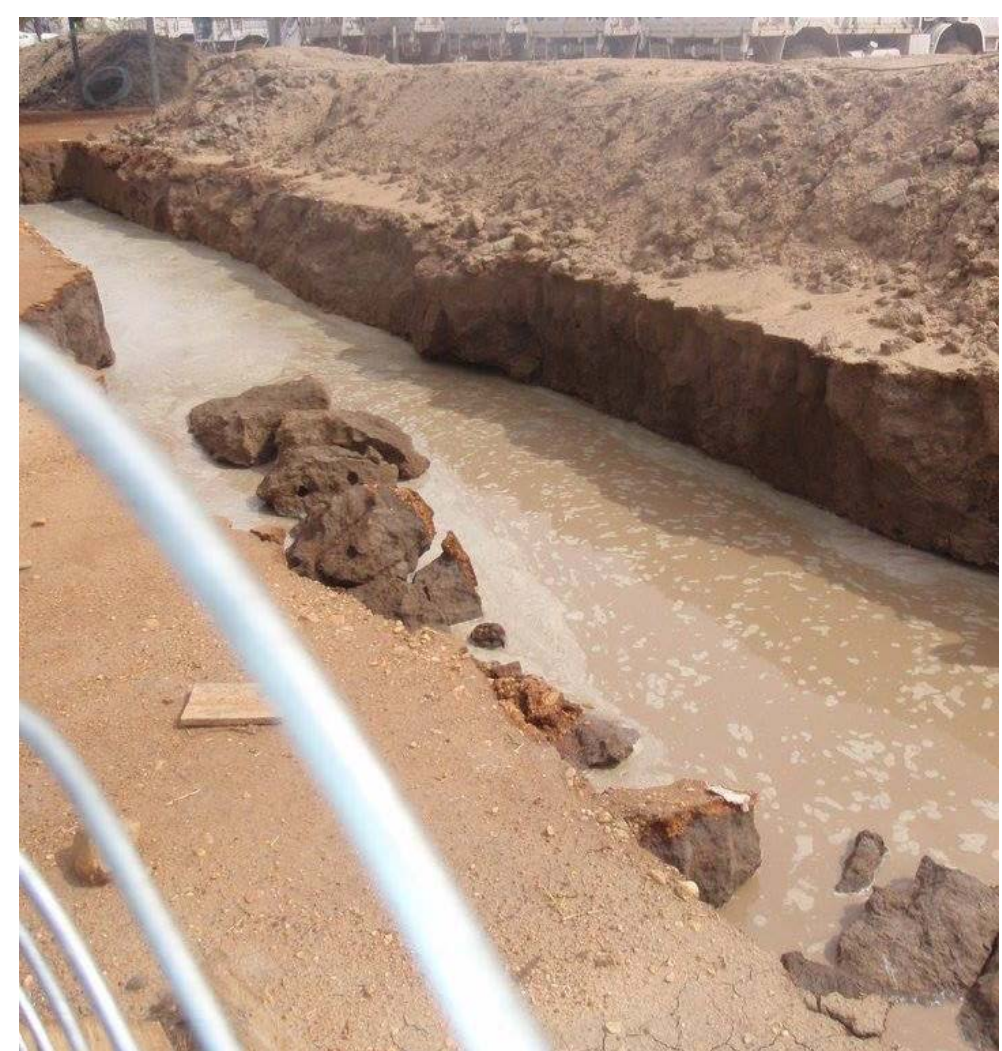

Figure 6: Security ditches filled with water (Source: V Hammond) 


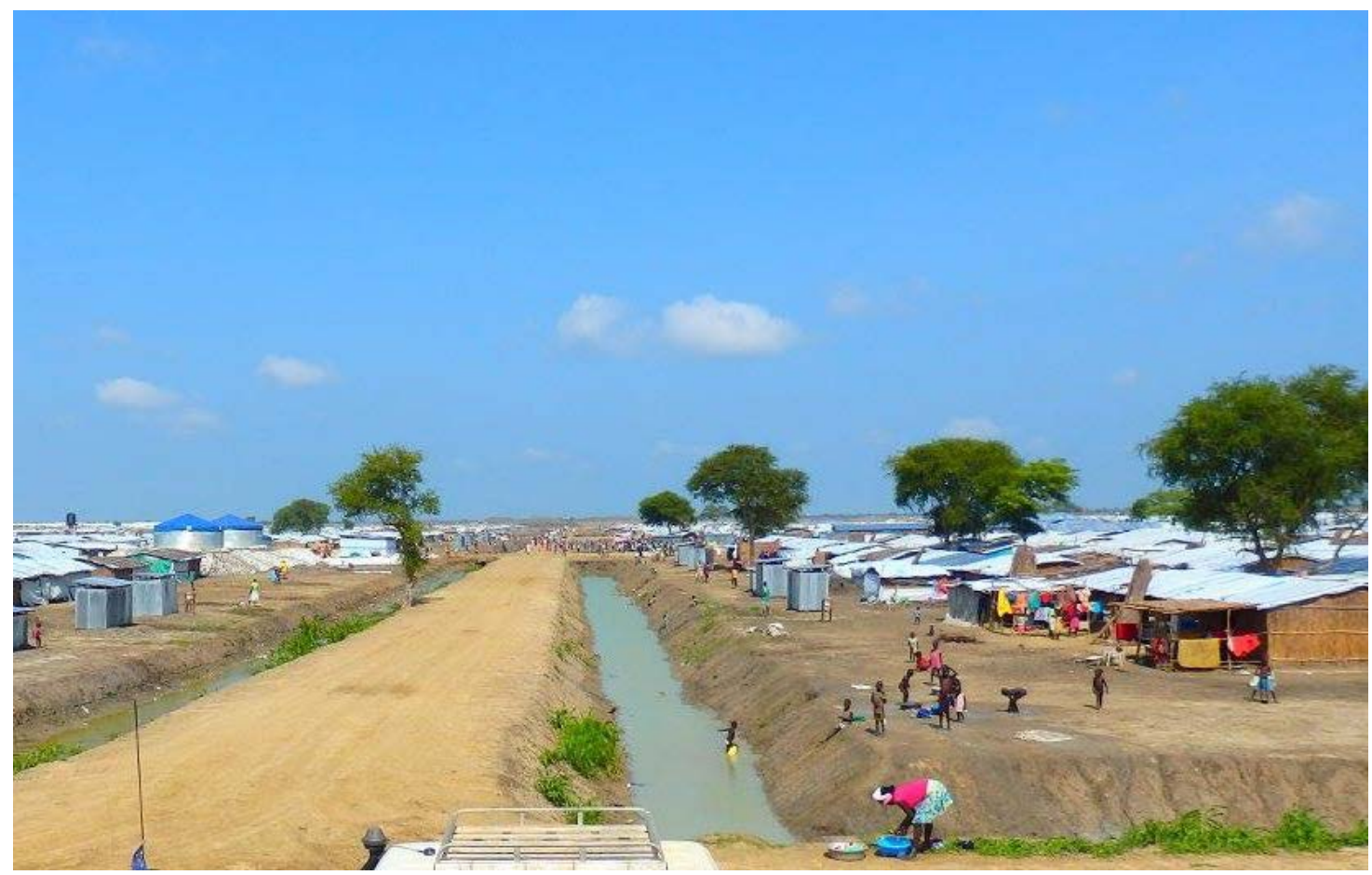

Figure 7: Ditch being used as a source of water (Source: V Hammond)

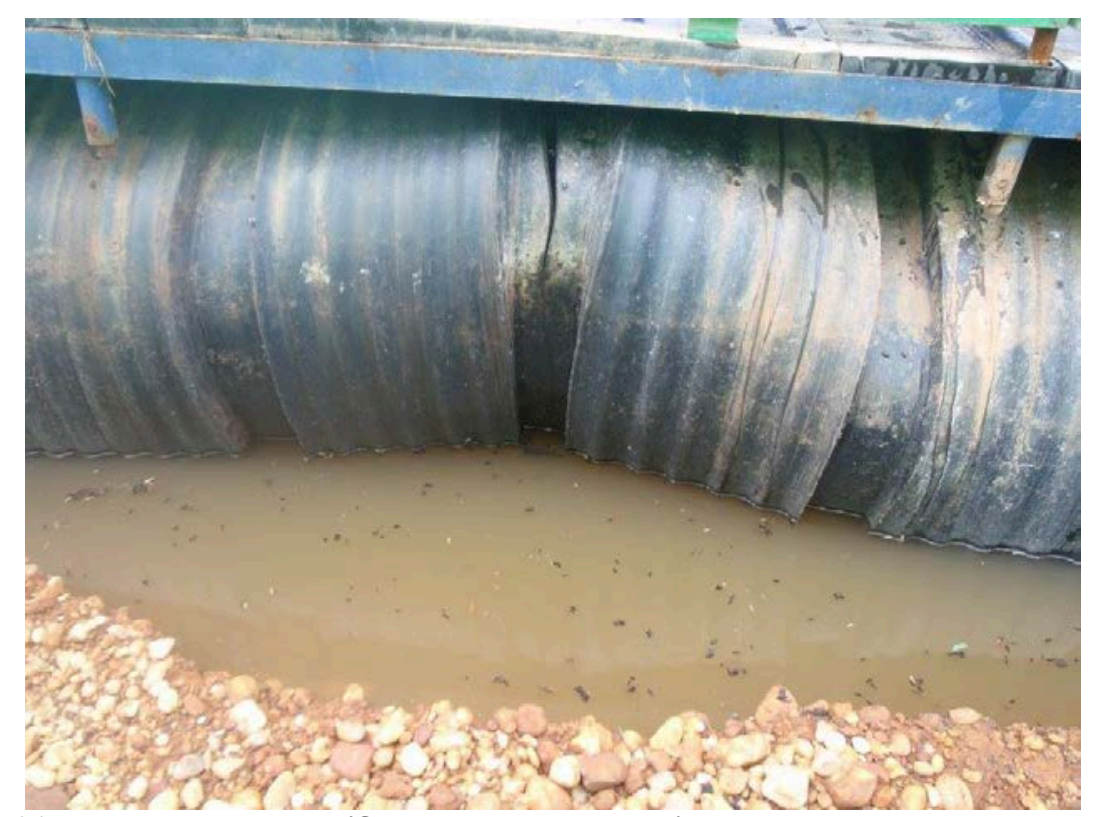

Figure 8: Flotation of faecal sludge tanks (Source: V Hammond)

\section{Existing guidance}

\subsection{Current standards}

\subsubsection{SPHERE}

In order to establish the extent of the problem, the SPHERE standards give a good benchmark. These are internationally agreed minimum standards in Humanitarian response. Whilst there is a section on drainage, most of the SPHERE guidance on drainage is scattered throughout the handbook. 
"Surface water in or near emergency settlements may come from household and water point wastewater, leaking toilets and sewers, rainwater or rising floodwater. The main health risks ... are contamination of water supplies and the living environment, damage to toilets and dwellings, vector breeding and drowning. Rainwater and rising floodwaters can worsen the drainage situation in a settlement and further increase the risk of contamination. A proper drainage plan, addressing stormwater drainage through site planning and wastewater disposal using small-scale, on-site drainage, should be implemented to reduce potential health risks to the population. ...

"Drainage standard 1

People have an environment in which the health and other risks posed by water erosion and standing water, including stormwater, floodwater, domestic wastewater and wastewater from medical facilities, are minimised.

Key actions

- Provide appropriate drainage facilities so that dwelling areas and water distribution points are kept free of standing wastewater and that stormwater drains are kept clear

- Seek an agreement with the affected population on how to deal with the drainage problem and provide sufficient numbers of appropriate tools for small drainage works and maintenance where necessary

- Ensure that all water points and hand washing facilities have effective drainage to prevent muddy conditions.

Key indicators

- Areas around dwellings and water points are kept free of standing wastewater, and stormwater drains are kept clear.

- Shelters, paths and water and sanitation facilities are not flooded or eroded by water.

- Water point drainage is well planned, built and maintained. This includes drainage from washing and bathing areas as well as water collection points.

- Drainage waters do not pollute existing surface or groundwater sources or cause erosion.

- Sufficient numbers of appropriate tools are provided for small drainage works and maintenance where necessary.

- Displaced populations are settled in locations that minimise their exposure to mosquitoes.

- Vector breeding and resting sites are modified where practicable.

- The population density of mosquitoes is kept low enough to avoid the risk of excessive transmission levels and infection.

- Displaced communities should also have access to sufficient tools to excavate surface water drainage channels

- Trees and other vegetation are retained where possible to increase water retention, minimise soil erosion and to provide shade." 


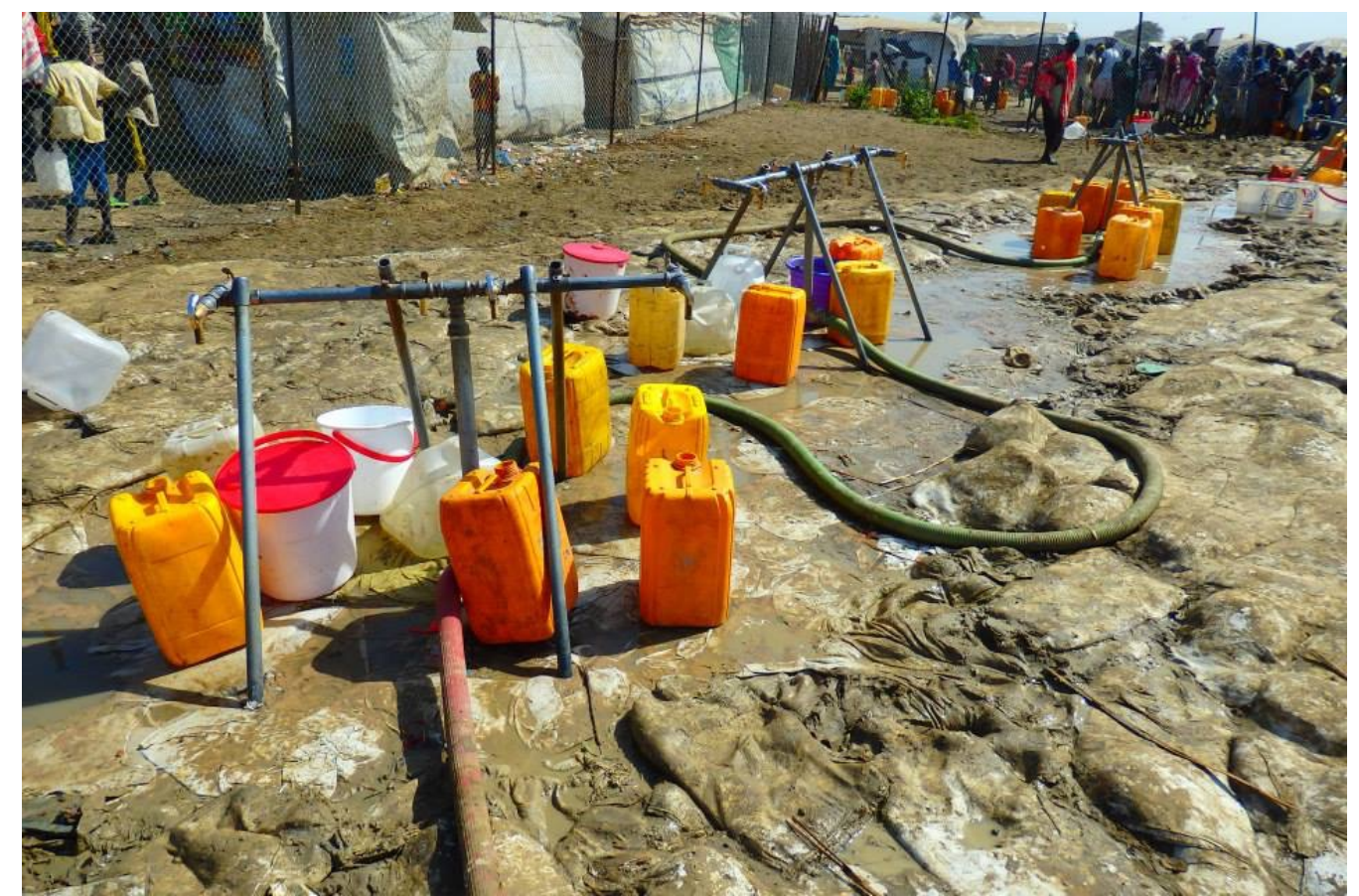

Figure 9: Poor drainage around water distribution points (Source: $V$ Hammond)

Thus the view of the focus group participants was confirmed by SPHERE, focusing on the problems rather than the causes of the problem, mixing up the different sources of water on the surface. The standards are also vague, with words like "appropriate" and "sufficient" and no indication how long water should be ponding before it becomes "standing water". This issue of ill-defined organisational boundaries continues in the rest of the chapter on Water Supply, Sanitation and Hygiene Promotion, relating to "Excreta disposal standard 1: environment free from human faeces"

"Key indicators

- In flood or high water table situations, appropriate measures are taken to tackle the problem of faecal contamination of groundwater sources.

- Drainage or spillage from defecation systems does not contaminate surface water [see figure 10] or shallow groundwater sources"

SPHERE (2011) 


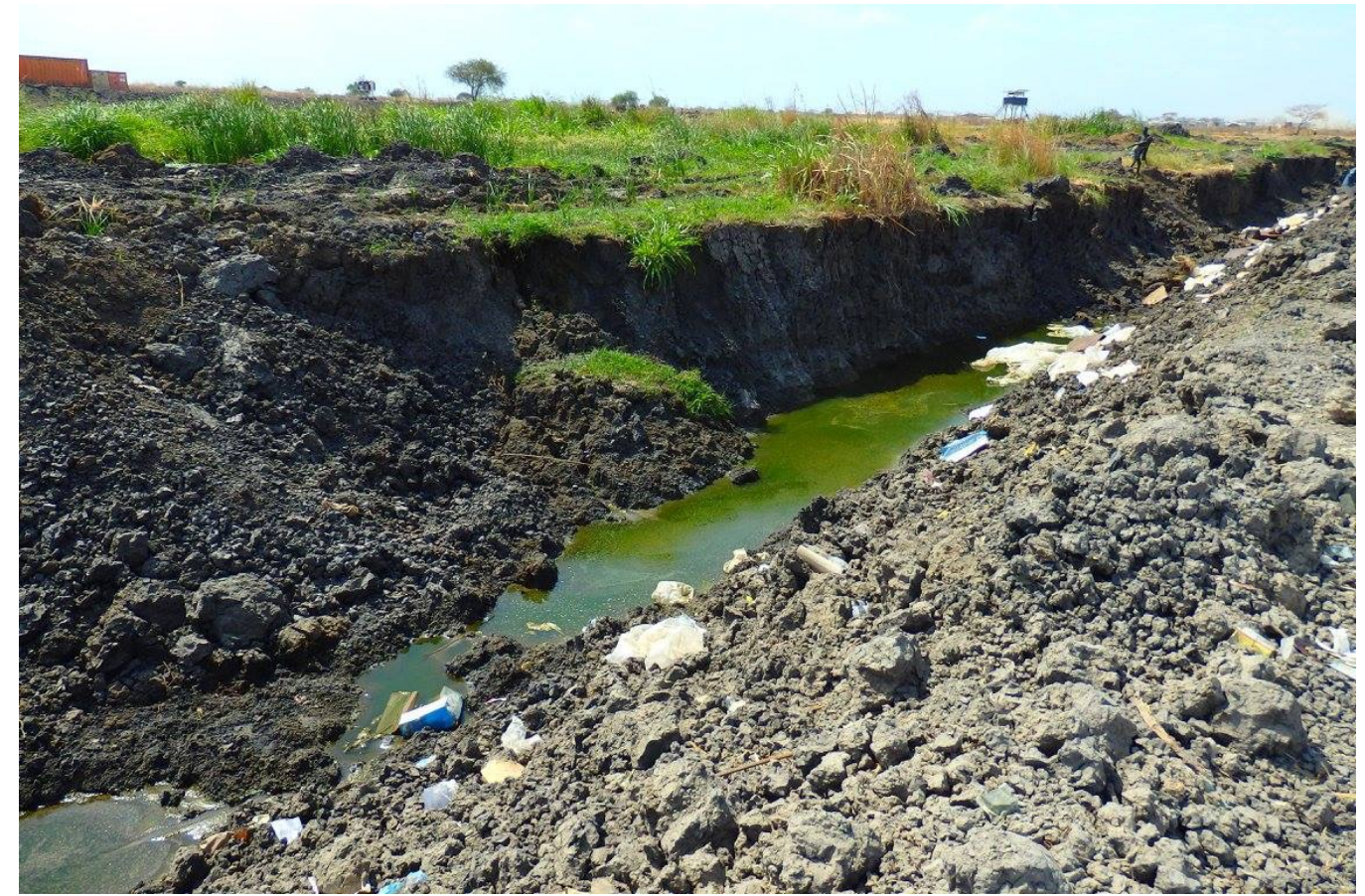

Figure 10: A ditch filled with sewage (Source: V Hammond)

Relating to "Vector control", the guidance notes say:

"With regard to malaria control, for example, camps should be located 1-2 km upwind from large breeding sites, such as swamps or lakes ...

"There are a number of basic environmental engineering measures that can be taken to reduce the opportunities for vector breeding. These include ... drainage of standing water, and clearing unwanted vegetation cover around open canals and ponds. ...

"Culex mosquitoes breed in stagnant water ..., Anopheles in relatively unpolluted surface water such as puddles, slow-flowing streams and wells, and Aedes in water receptacles such as bottles, buckets, tyres, etc. Examples of environmental mosquito control include good drainage, properly functioning ... latrines"

SPHERE (2011)

Relating to Solid Waste management (figure 11), the introduction states:

"Solid waste management ... can have a negative impact on the environment. ... the pollution of surface- and groundwater sources due to leachate from ... waste. ... Solid waste often blocks drainage channels and leads to an increased risk of flooding, resulting in environmental health problems associated with stagnant and polluted surface water. "

SPHERE (2011) 


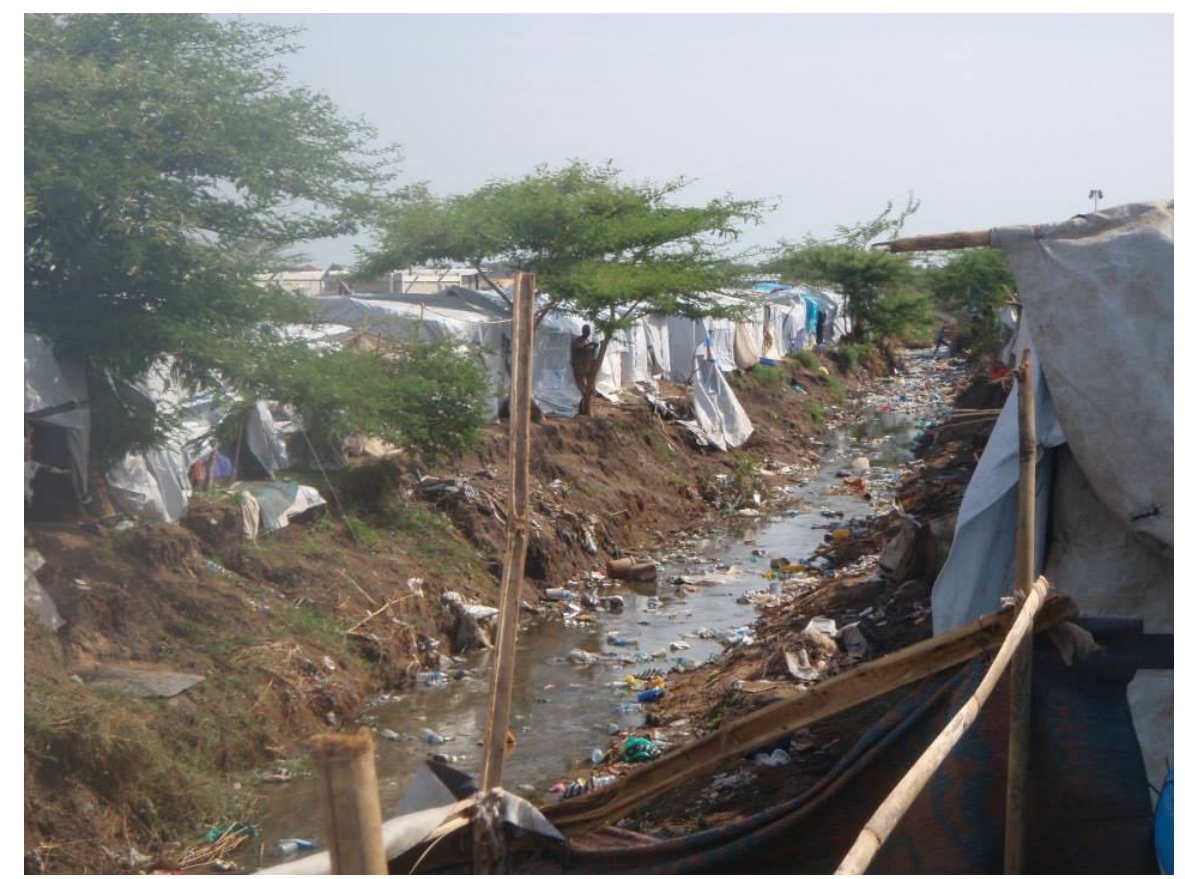

Figure 11: Solid waste in a drainage ditch (Source V Hammond)

Other sections (such as providing tools for the maintenance of shelters) reinforce the two conclusions from analysing the text; "ownership" of the problem is fragmented (with WASH, health, shelter, planning issues) and indicators for measuring achievement of any standards are lacking. The issue of responsibility is at the core of many of the technical issues.

\subsubsection{Other agencies and publications}

A similar pattern of concern but no detail is provided by looking at guidance from agencies and specialist publications. "Essential Water \& Sanitation Requirements for Camps" (MSF 2010) only mentions that rain and runoff water should be disposed of in natural drainage and this should be planned from the start. IFRC (Johns Hopkins, 2007) reference the SPHERE indicators. UNHCR (2008)

"strive to ensure ... minimum environmental damage ... prevention of pollution of local water sources and minimization of other environmental impacts due to water and sanitation-related activities to help develop a good rapport with the host community ... and controlled discharge and drainage of wastewater and storm-water to avoid water-induced hazards in the camp and the vicinity.

However, in their "Practical Guide to the Systematic Use of Standards and Indicators in UNHCR Operations" (UNHCR 2006), only water, latrines, showers and refuse pits are counted. The "environment" is measured by having an "Environmental Action Plan". The latest UNHCR Emergency handbook (2015) does not mention drainage under the WASH indicators and standards, although the third edition (2007) did mention drainage under shelter standards. "Emergency sanitation: assessment and programme design" (Harvey et al. 2002) does have examples of minimum objectives for sanitation facilities, but only for wastewater not surface water. It does mention drainage, but only in as far as it interacts with other sanitary facilities, such as latrines or wastewater disposal, For example: 
"In general, drainage channels should be constructed to ensure that the site does not become a swamp every time it rains. These channels may also be used to dispose of wastewater which may be diluted with rainwater. All drainage facilities must be adequately maintained and regular inspection and cleaning should be conducted."

(Harvey et al, 2002)

Interestingly however they have the following indicators under "hygiene promotion", which are from the drainage standards for SPHERE.

- "Areas around shelters and waterpoints are free of standing wastewater, and local wastewater drains are kept clear.

- People remove standing water from around their dwellings and living areas, and dispose of wastewater in an appropriate manner.

- There is a demand for tools for drainage works"

(Harvey et al, 2002)

\subsection{Current humanitarian solutions}

To get another perspective of the humanitarian situation, the range of possible solutions to surface water management in temporary settlements was examined. In SPHERE, the recommended text for drainage is "Design Manual: On-Site Wastewater Treatment and Disposal Systems" (EPA, 1980), which does not cover surface water drainage, only wastewater treatment. This is manual is not for humanitarian or even low-income country contexts but for the situation in the USA.

For Médecins san Frontières (MSF), Noortgate and Maes (2010) do have a chapter on "runoff water and wastewater", but only describe drainage channels and pipes in general terms, as do Semiond and Gonzalez, for Action Contre la Faim (ACF) and UNHCR (2007). IFRC (Johns Hopkins, 2007) précis the wastewater advice in Harvey et al (2002). Wisner and Adams (2003) only look at wastewater and sullage.

A more practical guide is Davis and Lambert (2002), but again, information on "rainfall runoff" in the WASH sections is limited, but more extensive advice is listed under "roads". A similar approach is taken by OXFAM (nd), drawing from literature on labour-intensive road building. It does briefly describe the "rational method" of drainage design. Nunn (2010) reports the British Army using this method but having problems getting local rainfall data. He also noted the standard army approach was to prepare, standardise and prefabricate as much infrastructure as possible. This worked well for structures such as buildings and bridges, and even roads, but the approach was not so suited to surface water, due to the influence of local climate and soils. The use of British design standards did not always transfer well to more intense rainfall areas. 


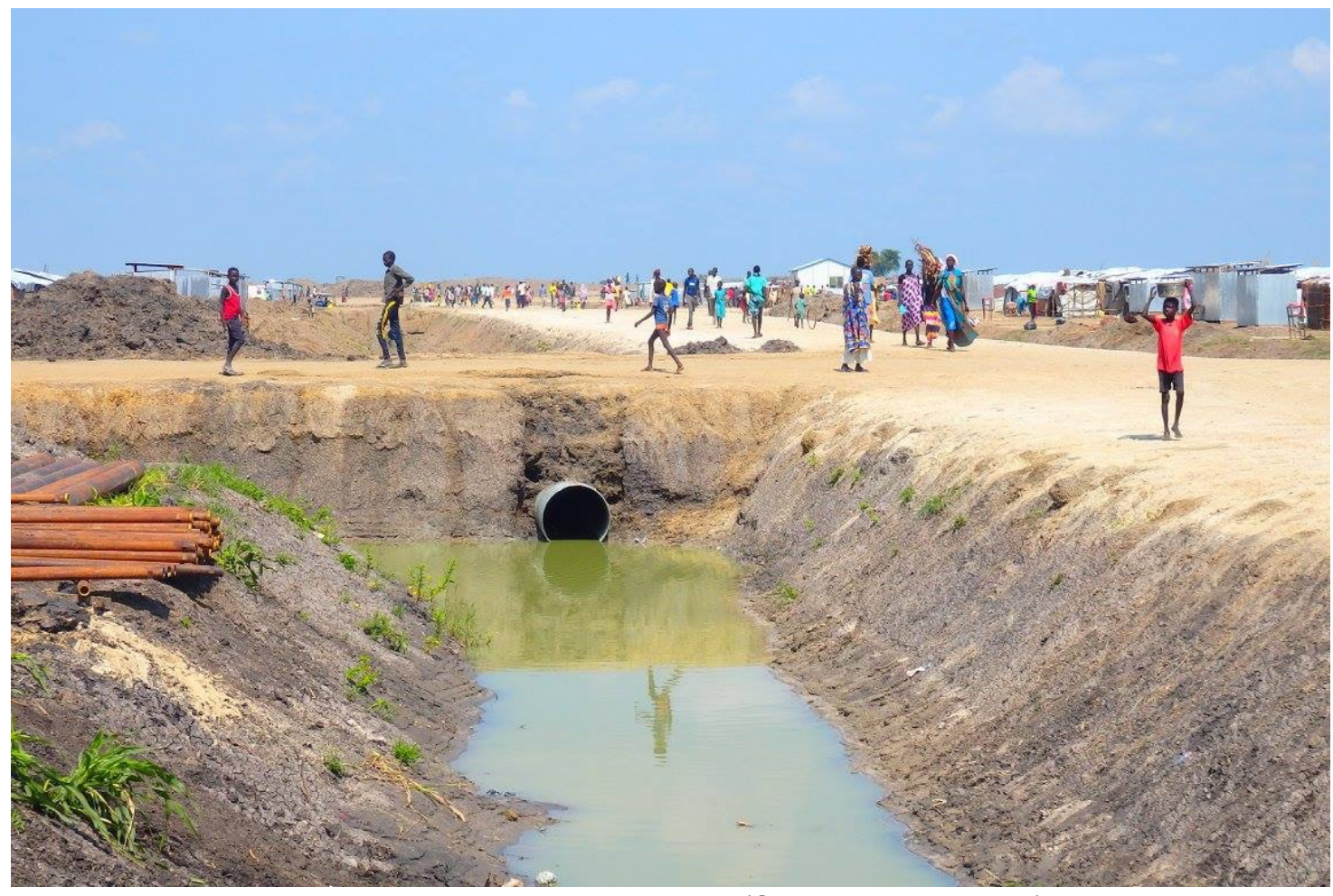

Figure 12: Road drainage may create vector breeding sites (Source V Hammond)

\subsection{Wider theoretical perspectives}

The approach to drainage being taken by Davis and Lambert (2002) or OXFAM (nd), using channels to convey water away is being superseded by more sustainable approaches, such as Sustainable Urban Drainage Systems (SUDS) (e.g. Armitage et al 2013). This brings a wider range of solutions, especially for balancing intense flows and providing some treatment, although vector breeding (figure 12) and faecally contaminated waters can be a concern (Reed 2013). These options are currently lacking in the humanitarian literature, although there sources in the development field (e.g. Parkinson and Mark 2005). The advantages of aligning drainage with the natural conditions should bring benefits in terms of more effective designs, but at a cost of more bespoke solutions and increased assessments. As more of the reported examples of drainage relate to failures rather than successes, this is potential rather than a reported solution.

\section{Other sectors}

\subsection{Site selection and planning}

The reference by Davis and Lambert (2002) to roads points to the issue that surface water does not respect physical or institutional boundaries. Reviewing other areas of SPHERE, in the chapter on shelter and settlement, the guidance on site selection and drainage is:

"Surface water drainage and the risks of ponding or flooding should be assessed when selecting sites and planning temporary communal settlements. The site gradient should not exceed 5 per cent, unless extensive drainage and erosion control measures are taken, or be less than 1 per cent to provide for adequate drainage [see figure 13]. Drainage channels may still be required to minimise flooding or ponding. The lowest point of the site should be not less than three metres above the estimated maximum level of the water table. 
The drainage sections notes that "Large-scale drainage is generally determined by site selection and development" (SPHERE, 2011). This is also explored in Lambert and Davis (2002), where topographical aspects of site selection are discussed. They also mention the use of contour bunds but their examples show a rigid block layout, with no allowance for drainage and not considering contours. This perspective is reiterated elsewhere (e.g. Assar 1971).

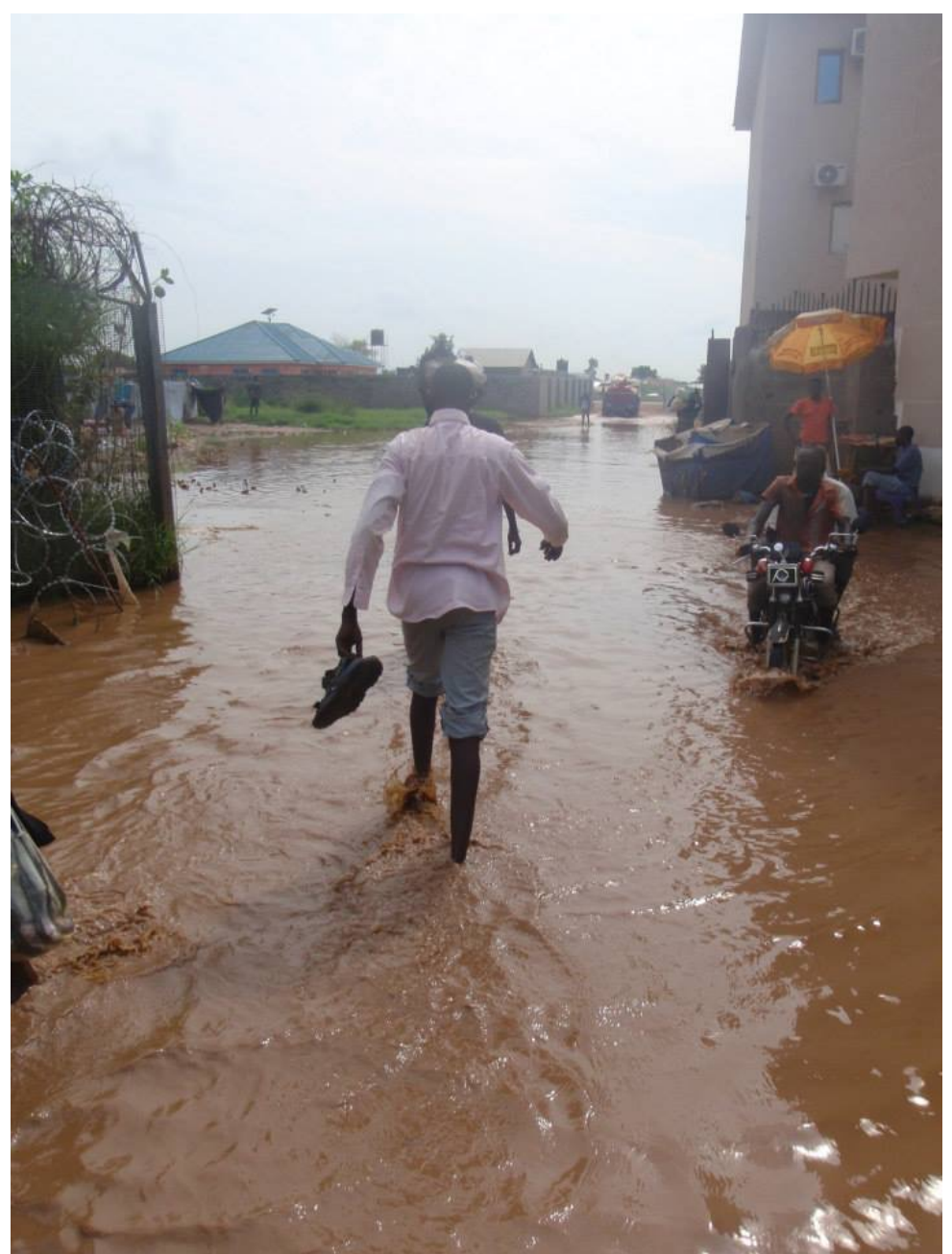

Figure 13: Wide scale inundation requires strategic planning rather than drains (Source: $V$ Hammond)

\subsection{Shelter}

At the other end of the scale, the SPHERE guidance on "Covered living space" includes:

"Surface-water drainage should be provided around the shelter and raised floors should be used to minimise the risk of water due to rain or snow melt from entering the covered area."

SPHERE (2011)

This was reinforced in the earlier edition of SPHERE, under Non-food items standard 5: tools and equipment:

"Typical tool sets: subject to local practices, typical tool sets could include a hammer or mallet, an axe or machete, and a spade or shovel. ... Displaced communities should also have access to sufficient tools to excavate surface water drainage channels and to handle the remains of the deceased as appropriate ..." 
(Sphere 2004)

Assar (1971) recommends digging drainage ditches around tents and alongside roads, but no further details are given. CEHA et al (1991) noted the actions of the refugees themselves in managing water locally.

"In the beginning, the refugees dug earth ditches around their tents and shelters to divert the rain water. Emergency teams of sanitation labourers and other volunteers, equipped with the necessary tools and protective clothing, toured the camps digging and clearing drains, ditches and culverts and giving necessary help to the refugees."

The mention of raising living space was also noted in Reed (2013), where people in low-income areas used small bunds to direct surface water away from their homes raised buildings in areas that regularly flooded.

\section{Discussion}

The pattern that emerged from the various information sources is often one of more questions than answers, but some themes emerged.

\subsection{Responsibility}

As mentioned earlier, the fact that drainage issues are in different sections of both the SPHERE standards and Davis and Lambert (2002) is indicative of a lack of institutional ownership. Under the cluster system, there are separate groupings for WASH (led by UNICEF), Health (led by WHO), Emergency Shelter (led by UNHCR and IFRC), and Camp management and co-ordination (led by UNHCR and IOM) yet drainage has implications for WASH, shelter, camping planning, non-food item distribution, roads and vector control. This results in a range of both standards and solutions, often poorly described and mixing differing forms of rainwater/ wastewater/ sullage. Besides the lack of clarity from an institutional and sectoral perspective, there is also the reality that flowing water does not respect administrative borders, so the source of a problem may be physically outside the control of an organisation, or the solution may lie outside the site, especially when security or political tensions limit action. This issue is reflected in other urban drainage research (Reed, 2013). Even in stable contexts, the management of urban drainage is spread between departments, with planners or road engineers having more influence but perhaps less knowledge than water engineers.

\subsection{Spatial and temporal variation}

The climate, soil and topographical conditions interact to create surface drainage problems. This limits the occurrence of the issue and therefore creates uncertainty if this is going to be a problem or not. This turn has an impact on management issues. Budgets need to relate to the need for drainage, including the distribution of non-food items if spades are required for digging. Staff training, monitoring and evaluation, site liaison and cluster activities, health risks and logistics all have to adjust in areas where surface water management is a problem, requiring a flexible approach.

Similarly, one aspect that Nunn (2010) discussed, was the difference between "off the shelf" designs and a more bespoke approach, again due to climate, soil and topographical conditions. This leads to a "site specific" response as a "one size fits all" philosophy will not be efficient or effective. This also puts a greater burden on 
the engineer working locally, as they have to carry out investigations before selecting a solution, rather than resorting to a standard design.

\subsection{Scale}

The different responsibilities and solutions can be looked at at three scales. At a macro scale, the whole site needs to be selected in relation to natural drainage paths and areas that are prone to flood. At a micro scale, the design of shelters and the area around each dwelling needs to consider rainfall runoff, raising living space, digging trenches or building bunds (figure 14). In between, on a meso scale, roads need to be drained and excess water conveyed away from shelters and other buildings. These nuances and connections are not emphasised in any of the guidance, with the shelter literature focusing on the micro, the WASH area focusing on the meso scale, and the planning on the macro scale. Any failures at the macro and meso scales problems end up in the homes of displaced people, at the micro scale. There is also a timing element to this, with the planning aspects being carried out early on in the process and the adverse impacts only being realised at a later date. This is mirrored in the cost implications, as site layout can easily be adjusted on paper before it is developed, but trying to hold back surface water when it starts to rain is not simple.

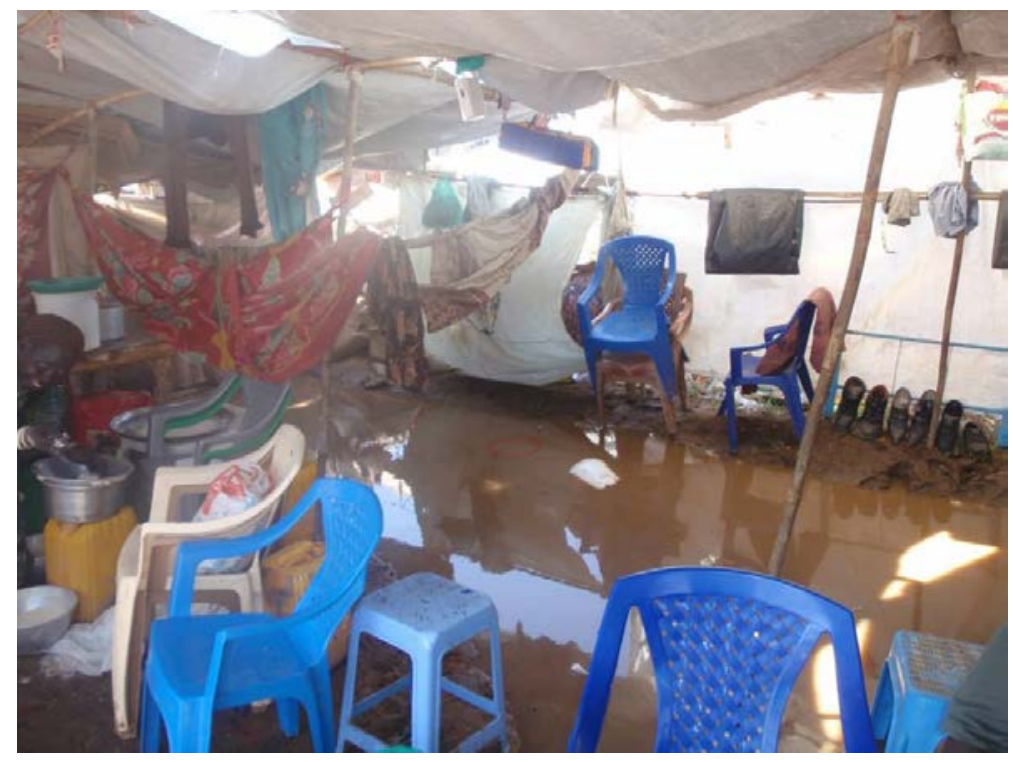

Figure 14: Inside a flooded temporary shelter (Source V Hammond)

\subsection{Guidance}

The final aspect to be discussed is the almost complete lack of accessible guidance on this issue. Whilst most of the standard texts mention the issue of poor surface water management, few give much attention to it. The most significant lack in this area is the reference given in the SPHERE (2011), which is not relevant technically or in terms of the humanitarian context. Even where there is guidance, this is incomplete technically and in scope, as well as not incorporating developments in surface water management that have evolved over the last 20 years.

Whilst technical guidance can be adapted from existing sources, a more sustainable solution will rely on the issue being examined from an organisational perspective. As such, the challenge is relate the physical 
management of water on the surface to the interests of a wide range of humanitarian actors. This is an issue of rights and protection of displaced people as much as it is of infiltration and ditches.

\section{Acknowledgements}

The author would like to acknowledge the contribution through numerous informal conversations and discussions in training sessions that have provided a view from the practical humanitarian context. Particular thanks to Victoria Hammond for her photographs.

\section{References}

Assar, M. (1971) Guide to Sanitation in Natural Disasters World Health Organization Geneva

Armitage, N., Vice, M., Fisher-Jeffes, L., Winter, K., Spiegel, A. and Dunstan J (2013) Alternative Technology for Stormwater Management: The South African Guidelines for Sustainable Drainage Systems WRC Report No. TT 558/13 Water Research Commission Pretoria South Africa

Azurin JC, Alvero M. (1974) Field evaluation of environmental sanitation measures against cholera. Bull World Health Organ. 1974;51(1):19-26.

Bastable, A. and Russell, L, (2013) Gap Analysis in Emergency Water, Sanitation and Hygiene Promotion. Humanitarian Innovation Fund, London UK

Centre for Environment Health Activities (CEHA), WHO World Health Organization and United Nations Environment Programme (UNEP) (1991) Manual on water and sanitation for health in refugee camps. WHO/EMRO/CEHA \& UNEP Amman, Jordan

Davis, J., \& Lambert, R. (2002). Engineering in Emergencies - A Practical Guide for Relief Workers. 2nd edition Intermediate Technology Publications Ltd. London, UK:

Environmental Protection Agency (EPA) (1980), Design Manual: On-Site Wastewater Treatment and Disposal Systems, Report EPA-600/2-78-173. Cincinnati, USA.

Harvey, P., Baghri, S., \& Reed, B. (2002). Emergency Sanitation - Assessment and Programme Design.: WEDC. Loughborough, UK

Johns Hopkins Bloomberg School of Public Health (2007) The Johns Hopkins and Red Cross Red Crescent Public Health Guide in emergencies International Federation of Red Cross and Red Crescent Societies. Geneva, Switzerland

McDonald, J. D. (1983) "Looking back": environmental health in Nottingham, 1847-1983 Nottingham City Council, Environmental Health Dept Nottingham UK 1983

MSF (2010) Essential Water \& Sanitation Requirements for Camps (2010) Médecins Sans Frontières

Noortgate, J van den and Maes, P (ed) (2010) Public health engineering in precarious situations (2nd ed) Médecins Sans Frontières Paris, France

Nunn C (2010) Emergency Drainage Infrastructure for Civilian and Military base camps Unpublished BEng thesis, Loughborough University, Loughborough UK

OXFAM (no date) Low cost drainage for emergencies Available from http://policypractice.oxfam.org.uk/publications/low-cost-drainage-for-emergencies-126717 [Accessed August 2015]

Parkinson J. and Mark O (2005) Urban Stormwater Management in Developing Countries IWA London UK

Phelps, R.D.S. and Griggs, J (2005) Mound filter systems for the treatment of domestic wastewater (BR 48) Building Research Establishment (BRE) Watford, UK

Reed, BJ. (2013) Storm-water management in low-income countries, Proceedings of the ICE - Municipal Engineer,, Volume 166,(Issue 2), pp.111-120

Reed, B.J., Parkinson, J and Nalubega, M (2001) People and puddles: is drainage important? In: EDITOR(S) People and Systems for Water, Sanitation and Health. $27^{\text {th }}$ WEDC International Conference, Lusaka, Zambia Loughborough UK WEDC, Loughborough University pp 344-247

The Sphere Project (2004) Humanitarian Charter and minimum standards in humanitarian response $2^{\text {nd }}$ edition. The Sphere Project/Practical Action Publishing Geneva, Switzerland

The Sphere Project (2011) Humanitarian Charter and minimum standards in humanitarian response $3^{\text {rd }}$ edition The Sphere Project/Practical Action Publishing Geneva, Switzerland

Semiond, H., Gonzalez, F (ed) Action Contre la Faim (ACF): (2005) Water, sanitation and hygiene for populations at risk (2nd edn) Hermann, Paris, France

Taylor DL, Kahawita TM, Cairncross S, Ensink JHJ (2015) The Impact of Water, Sanitation and Hygiene Interventions to Control Cholera: A Systematic Review. PLoS ONE 10(8):

Taylor DL (August 2015) personal communication

UNHCR (2006), Practical Guide to the Systematic Use of Standards and Indicators in UNHCR Operations. United Nations High Commissioner for Refugees, Geneva, Switzerland 
UNHCR (2007) Handbook for Emergencies $3^{\text {rd }}$ ed United Nations High Commissioner for Refugees, Geneva, Switzerland

UNHCR (2008) A Guidance for UNHCR Field Operations on Water and Sanitation Services, Water and Sanitation Unit Public Health \& HIV Unit, UNHCR Geneva Switzerland

UNHCR (2015) Emergency handbook $4^{\text {th }}$ ed United Nations High Commissioner for Refugees, Geneva, Switzerland Available from https://emergency.unhcr.org/ [Accessed August 2015]

Wisner, B. and Adams, J. (ed) (2002) Environmental health in emergencies and disasters: a practical guide World Health Organization (WHO) Geneva, Switzerland

Figure captions

Figure 1: Ponding surface water causing a poor living environment (Source: $V$ Hammond)

Figure 2: Poor drainage hinders transport (Source: $\vee$ Hammond)

Figure 3: Erosion of road due to runoff from a camp (Source: $V$ Hammond)

Figure 4: Surface water flooding in a camp for displaced people (Source: V Hammond)

Figure 5: Erosion of a pit latrine (Source: $\vee$ Hammond)

Figure 6: Security ditches filled with water (Source: V Hammond)

Figure 7: Ditch being used as a source of water (Source: $V$ Hammond)

Figure 8: Flotation of faecal sludge tanks (Source: $V$ Hammond)

Figure 9: Poor drainage around water distribution points (Source: $V$ Hammond)

Figure 10: A ditch filled with sewage (Source: $V$ Hammond)

Figure 11: Solid waste in a drainage ditch (Source $V$ Hammond)

Figure 12: Road drainage may create vector breeding sites (Source $V$ Hammond)

Figure 13: Wide scale inundation requires strategic planning rather than drains (Source: $V$ Hammond)

Figure 14: Inside a flooded temporary Shelter (Source V Hammond) 